\title{
Noticia de las principales novedades de la nueva Ley de Sociedades Laborales y Participadas
}

\author{
Javier Divar Garteiz Aurrecoa \\ Doctor en Derecho. Profesor Emérito de la Universidad de Deusto. \\ Presidente de la Asociación Internacional de Derecho Cooperativo.
}

Sumario: 1. Objetivos de la reforma. 2. Novedades de la reforma. 2.1. Sociedades participadas. 2.2. Sociedades laborales de dos socios. 2.3. Personas jurídicas como partícipes de Sociedades Laborales. 2.4. Facilidades administrativas. 3. Beneficios fiscales y fomento del tipo societario. 4. Adaptación de los Estatutos societarios a la nueva Ley.

Resumen: Con la promulgación de la nueva Ley de Sociedades Laborales y Participadas se presentan algunas novedades que tienen como objetivo la adecuación de la actual legislación a los cambios producidos en la normativa del Derecho de Sociedades. Se trata de una serie de medidas que abarcan desde la propia denominación de la Ley hasta la introducción de novedades en la regulación del capital, pasando por una simplificación de la tramitación de carácter administrativo.

Palabras clave: Reforma, Sociedades Laborales y Participadas.

Abstract: With the approval of the new Labour and investee companies act are presented some developments that are aimed at the adequacy of the changes of the current legislation in the regulations of the company law. Measures ranging from the own name of the law to the introduction of new developments in the regulation of the capital, passing through a simplification of the administrative processing.

Keywords: Reform, labour and investee companies. 


\section{Objetivos de la reforma}

En primer lugar la reforma legal, como indica la propia exposición de motivos de la nueva Ley 44/2015, de 14 de octubre, tiene como objeto la adecuación de la legislación vigente de sociedades laborales a los cambios de la normativa general del Derecho de sociedades (y fundamentalmente la contenida en la Ley de Modificaciones estructurales de las sociedades mercantiles y el Real Decreto legislativo de modificación de la Ley de Sociedades de capital).

Además la reforma se aprovecha para atender a la disposición adicional séptima de la Ley de Economía Social, del 29 de marzo de 2011, respecto a la obligación gubernamental de adecuación de las sociedades laborales y a su fomento.

Por último se aprovecha la reforma para atender a las recomendaciones de la UE para fomentar la participación de los trabajadores en las empresas (Recomendación del Consejo del 27 de julio de 1992 y Dictamen del Comité Económico y Social Europeo del 21 de octubre de 2010, acordes con la Estrategia Europa 2020, sobre la implementación en la Unión de un futuro sostenible).

\section{Novedades de la reforma}

\subsection{Sociedades Participadas}

La primera novedad se deriva ya de la misma denominación de la Ley, que no se refiere sólo a las sociedades laborales sino también a las sociedades participadas por sus trabajadores (se delimitan como tales a aquellas sociedades de capital en las que los empleados ostenten participaciones no superiores al cincuenta por ciento del mismo, es decir, se trata de sociedades participadas por sus trabajadores pero que no alcanzan los requisitos legales para ser calificadas como laborales).

Esta delimitación societaria, pionera en el Derecho interno, se recoge separadamente en el Capítulo III. ${ }^{\circ}$ de la nueva Ley (artículos 18 a 20), pero no se desarrolla, sino que ello se deja a una posterior regulación a la que se da competencia al Gobierno en la disposición final quinta.

El propio reconocimiento de estas sociedades se deja también (artículo 20) a un procedimiento para cuyo desarrollo reglamentario se habilita al Ministerio de Empleo y Seguridad Social.

En conclusión, estamos ante una mera cita legal del reconocimiento de la participación de los trabajadores en las sociedades mercantiles, 
que no tiene reconocimientos objetivos, haciendo dejación de esos derechos a la normativa complementaria, lo que supone una indudable inseguridad jurídica para los partícipes (todo dependerá de la sensibilidad al efecto del Gobierno correspondiente).

\subsection{Sociedades Laborales de dos socios}

El extenso artículo $1 .^{\circ}$ de la Ley, en la línea ya abierta por el Derecho cooperativo interno, recoge la posibilidad de constituir sociedades laborales con tan solo dos socios, que lo serán al 50\% en capital y voto, debiendo normalizar la sociedad a los parámetros de las sociedades laborales ordinarias en un término máximo de 36 meses.

\subsection{Personas jurídicas como partícipes de Sociedades Laborales}

El mismo artículo $1 .^{\circ}$ (al establecer las excepciones a que en las sociedades laborales ningún socio trabajador ostente más de un tercio del capital), permite también (con el límite en el 50\% del capital) que en las sociedades laborales puedan ser socios las entidades públicas, las personas jurídicas sin ánimo de lucro y las de economía social.

Ello abre una importante vía de colaboración para que las Administraciones públicas (como medida de fomento del empleo en su ámbito), las asociaciones y fundaciones, o las propias sociedades laborales o cooperativas, puedan ser partícipes a su vez de estas sociedades de la economía social.

\subsection{Facilidades administrativas}

Se simplifica la documentación exigible para obtener la calificación e inscripción de las Sociedades laborales (artículos 2 y 4 de la Ley), posibilitando las comunicaciones por medios informáticos y telemáticos.

También se limitan los casos de comunicación necesaria al registro administrativo de transmisiones de acciones o participaciones sociales.

\subsection{Novedades en la regulación del capital}

Se modifica el sistema para la transmisión voluntaria del capital, al efecto de agilizar la adquisición por los socios (trabajadores o no), al 
propio tiempo que se aprovecha la reforma para suprimir el derecho de preferencia de los trabajadores de duración determinada (artículo 6. ${ }^{\circ}$ ).

Se precisa la forma de valoración de acciones y participaciones, permitiendo que los estatutos de la sociedad establezcan criterios previos para la fijación de valores (artículo $7 .^{\circ}$ ).

Se autoriza a los estatutos sociales a reconocer a los socios el derecho de separación en todo momento, derecho que podrá limitarse (así como el de transmisión de capital) por un plazo no superior a cinco años desde la constitución de la sociedad (también, por supuesto, vía estatutaria).

Para los casos de embargos o prendas de acciones o participaciones, exige la nueva Ley que las notificaciones previstas en la Ley de Sociedades de capital (artículo 109 de la misma) se hagan también a los trabajadores no socios con contrato indefinido.

En los casos de transmisión «mortis causa» de capital se regula (artículo 10) que los estatutos sociales podrán establecer valores razonables, determinados conforme a criterios de valoración (a valor al día de fallecimiento del socio), superando los criterios de valor real de la legislación vigente de Sociedades laborales.

El derecho de suscripción preferente queda excluido (artículo 11) cuando los aumentos de capital tengan como objeto el mantenimiento de los mínimos legales para sostener el carácter de la sociedad como laboral, lo que implica una novedad respecto a la actual regulación.

Otra importante novedad es la permisión a estas sociedades de la autocartera (artículo 12. ${ }^{\circ}$ ), que deberá efectuarse con cargo a beneficios, a la reserva especial o a reservas disponibles.

Se limita la obligatoria dotación de la reserva especial (artículo 14) cuando ésta alcance un importe superior al doble del capital social. Pero se determina que la falta de dotación o su utilización indebida puede ser causa de descalificación de la sociedad como laboral.

Por último, la reforma prevista determina los casos de separación y exclusión de socios (artículo 16), lo que no está regulado en la legislación que ahora se deroga.

\section{Beneficios fiscales y fomento del tipo societario}

El capítulo II de la nueva Ley (que contiene como único artículo el 17) prevé que las sociedades calificadas como laborales tendrán un beneficio del $99 \%$ en la cuota del impuesto de transmisiones patrimoniales y actos jurídicos documentados en las transmisiones onerosas por adquisiciones de la empresa de la que originalmente proceda la mayoría de los socios trabajadores de la sociedad laboral. 
Colateralmente, la disposición adicional tercera del Anteproyecto establece que no existe transmisión en la subrogación arrendaticia de la sociedad, tanto al ser calificada como tal como tampoco en su posible descalificación.

Por su parte, la disposición adicional cuarta se dedica a las medidas de fomento de las sociedades laborales, lo que se manifiesta en la práctica como una necesidad imperiosa para este tipo societario, que en el contexto de la actual crisis económica se ha reducido muy notablemente.

A principios de 2008 , se contabilizaban más de 20.000 sociedades laborales. A principios de este año de 2015 no llegan a las 10.000.

Por lo que respecta al empleo, la bajada también es muy grave, puesto que se ha pasado de 125.000 trabajadores a solo 65.000.

No debemos olvidar que a este fomento obliga la Constitución (su artículo 129.2) a todas las Administraciones públicas, ya que estamos ante un caso propio de participación de los trabajadores en la empresa.

Es destacable que en relación al fomento de las sociedades laborales la citada disposición adicional $4 .^{a}$ de la Ley haga una mera referencia a la Ley de Economía Social.

También cita esa disposición a los regímenes forales del País Vasco y de Navarra, en una invitación (y reconocimiento competencial) a las medidas de fomento de los mismos.

En línea con lo anterior, es también destacable que la disposición adicional $6{ }^{a}$ de la Ley se dedique específicamente al régimen fiscal vasco, reconociendo que los beneficios fiscales en la Comunidad Autónoma del País Vasco «se regirán por la Ley 12/2002, de 23 de mayo, por la que se aprueba el Concierto Económico con la Comunidad Autónoma del País Vasco».

\section{Adaptación de los Estatutos societarios a la nueva ley}

La disposición final $6 .^{\text {a }}$ de la Ley establece que la misma entrará en vigor a los 30 días de su publicación en el Boletín Oficial del Estado (se ha publicado en el del 15 de octubre).

Desde su entrada en vigor, establece la disposición transitoria 2. ${ }^{a}$, las sociedades laborales tendrán dos años para adaptar sus estatutos sociales a la nueva Ley.

En cuanto a los procedimientos administrativos anteriores a la vigencia de la nueva Ley, la transitoria $1 .^{\text {a }}$ establece que se sustanciarán conforme a la normativa del momento de su inicio. 